\title{
João Cabral e o flamenco ou a arte de fazer no extremo
}

\author{
João Cabral and flamenco or the art of \\ doing in the extreme
}

Nylcéa Thereza de Siqueira Pedra

RESUMO

\begin{abstract}
Nos anos vividos na Espanha, João Cabral se apropria das artes populares do país de maneira muito particular. O exercício de aproximação ao flamenco se faz por meio da experimentação de noites nos tablaos e nas cuevas, mas também pelo estudo meticuloso do poeta artífice, dando origem a uma série de poemas que relacionam esta arte popular espanhola à arte de compor versos. No presente artigo nos propomos a traçar as relações entre a arte flamenca e o seu eco nos poemas cabralinos. Mais do que temática, a presença do flamenco é a oportunidade de o poeta construir outro dos seus símiles.
\end{abstract}

Palavras-chave: João Cabral de Melo Neto; Flamenco; Poesia.

\section{ABSTRACT}

In the years spent in Spain, João Cabral appropriates the country's popular arts in a very particular way. The exercise of approaching flamenco, not only through experiencing the nights in the tablaos and cuevas, but also by the meticulous study of the poet, lead to a series of poems that relates this Spanish folk art to the art of composing verses. In this article, we aim to trace the relationship between flamenco art and its echo in Cabral's poems. More than just a theme, flamenco is the opportunity for the poet to build another simile.

Keywords: João Cabral de Melo Neto; Flamenco; Poetry.

1 Universidade Federal do Paraná, Curitiba, Paraná, Brasil. E-mail: npedra@hotmail.com 

iversas têm sido as proposições sobre a origem do flamenco ao longo da História. Atualmente, os estudiosos se dividem entre aqueles que compreendem o flamenco como um elemento da cultura autóctone da Andaluzia e os que o consideram resultado do encontro cultural de várias etnias - fenícios, ciganos, judeus, árabes, mouros - no espaço andaluz. Qualquer que seja a teorização historiográfica mais acertada, o fato é que o flamenco é, hoje, considerado a expressão mais autêntica do povo e do espaço andaluz e, ao lado da corrida de toros, forma a dupla e a mais intensa imagem da Espanha folclorista.

A origem popular das duas artes proporciona-lhes, não poucas vezes, o trato de arte menor, sendo reduzidos os estudos críticos sobre elas. Entretanto, se com o tempo a arte do toreo foi recebendo maior atenção e cuidado da crítica, em uma breve análise dos estudos realizados sobre o flamenco, confirmamos o seu caráter esparso, e também que grande parte deles é realizado pelo olhar estrangeiro.

Se é impossível precisar a data de aparecimento do flamenco, o primeiro comentário sobre esta arte registra-se no último terço do século XVIII, nas Cartas Marruecas de José Cadalso, nas quais a correspondência entre dois marroquinos evidencia elementos da história e da cultura espanholas. Somente 
N. T. S. PEDRA João Cabral e o flamenco ou a arte de fazer no extremo no começo do século XIX, na obra Viaje por España de Charles Davillier e Gustave Doré, aparecem registros e análises dos componentes técnicos do flamenco, abandonando-se a impressão pessoal das Cartas Marruecas. É a partir de então que o flamenco recebe o estatuto de arte e passa a ser motivo de estudos críticos que ora destacam a sua técnica, ora a sua história, ora a sua profissionalização. No que todos coincidem, no entanto, é que o flamenco caracteriza-se como a arte da espontaneidade.

Os paralelos que podem ser estabelecidos entre a corrida de toros e o flamenco não são casuais, afinal ambas as artes compartilham um mesmo e complementar universo, como confirmam as palavras do escritor José Bergamín: "tanto o cante quanto o baile são acompanhantes invisíveis, inaudíveis, inseparáveis da arte de torear" (BERGAMÍN apud COBALEDA, p. 265). Essa relação vai além do tradicional encontro de toureiros no Tablao flamenco depois de uma tarde de touros ${ }^{3}$ e se encontra nas expressões taurinas utilizadas no cante, no "olé" expresso nas duas artes e, fundamentalmente, nas figuras do toureiro, do cantaor e da bailaora que compartilham a condição efêmera e intensa que as suas artes representam.

João Cabral adota uma aproximação que lhe é característica ao se aproximar da arte do flamenco. Com o cuidado que lhe é caro, separa cada uma das partes que o compõem e, desnudando a bailaora andaluza, reduzindo o cante ao seu palo mais seco, encontra uma lição de poesia. Neste exercício, o poeta considera a relação mantida entre o toreo e o flamenco e podemos ler em pelo menos cinco dos seus poemas dedicados ao tema ${ }^{4}$ as analogias estabelecidas entre ambos.

Preciso e extremo são os adjetivos mais empregados na justaposição realizada por João Cabral entre as duas artes. O poeta vai além, e nos jogos dos símiles, corrida de toros, flamenco e arte poética recebem as mesmas caracterizações e se fazem imagem uma das outras. Deste modo, o cante agudo, reto e penetrante é como a luta precisa entre toureiro e touro no "Diálogo" (p. 138-140) mantido entre eles (como à procura do nada/ é a luta também vazia/ entre o toureiro e o touro,/vazia, embora precisa); a bailaora é como um touro de lidia, que desafia quem a modele (A primeira das estátuas/ que ela é, quando começa,/parece desafiar/alguma presença interna//que no fundo dela próprial fluindo, informe e sem regra,/por sua vez a desafia/a ver quem ela modela $)^{5}$; e o cantaor é como o toureiro que existe no risco extremo

2 “(...) tanto el cante como el baile flamenco son acompañantes invisibles, inaudibles, inseparables del arte de torear".

3 “(...) después de presenciar la corrida de toros, es tradicional que los buenos aficionados se reúnan y comenten que hay que rematar la noche acudiendo a algún 'Tablao flamenco'” (ARREOLA, 1990, p. 13).

4 A saber: "Diálogo" (p. 138-140); "Estudos para uma bailadora andaluza" (p. 195-201); "A Antonio Mairena, cantador de flamenco" (p. 511-512); "Na cava, em Triana” (p. 633-634) e "Carmen Amaya, de Triana" (p. 641-642).

Revista Letras, 5 "Estudos para uma bailadora andaluza" (p. 195-201).
Curitiba, UFPR, n. 102 , pp. $27-46$, jul./dez. 2020 ISSN 2236-0999 (versão eletrônica) 
do desafio (Existir como quem se arrisca/como nesse cante em que se atiral/ (...) // ele não pode qualquer falha/ sem que desse mastro não caia $)^{6}$.

Aproximando o jogo de imagens, mais especificamente, à relação estabelecida entre o flamenco e a arte poética, observamos que, como já dissemos, passa pelo cuidadoso trabalho do poeta que disseca com olhar agudo cada uma das partes que o constituem. Em entrevista a Nicolás Extremera Tapia e Luisa Trias João Cabral afirma: "A Espanha tem esta coisa que para mim é um segredo: o popular. Não sei se foi Ortega que disse 'en España lo que no es popular es pedantería'. É esta coisa do popular no cante flamenco que me entusiasma" (MELO NETO apud EXTREMERA TAPIA e TRIAS, 1993, p. 57). Além de destacar a importância da arte flamenca em sua obra, o poeta retoma e reforça a premissa da importância que os elementos populares assumem na sua poética.

O caráter popular do flamenco é indiscutível e há os que defendam que a sua origem está na mistura de muitas vozes "dos filhos das sombras, os habitantes das cuevas, das prisões, das minas, dos prostíbulos" (MARTÍNEZ HERNÁNDEZ, 2004, p. 40). A síntese poética feita por João Cabral sobre o lugar e as pessoas do flamenco pode ser lida em poemas como "Habitar o flamenco" (p. 368-369) e "Na cava, em Triana" (p. 633-634) nos quais a gente espigada e morena de todos os sotaques usa um falar com coisas, sempre em um tempo aceso e extremo. Vale a pena determo-nos um pouco no poema "Habitar o flamenco" (p.368-369):

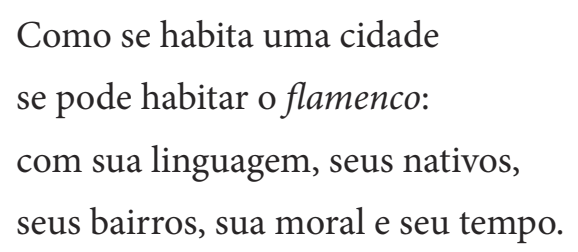

Já no primeiro verso do poema verificamos a presença de um verbo que se faz recorrente a partir da aproximação de João Cabral ao universo espanhol: habitar. Um habitar sinônimo do conhecer intimamente, que se constrói na medida em que se vive o lugar - ou a arte - habitado. Interessante, no entanto, que este conhecimento construído, porque habitado, só pode ser explicado se decomposto. É assim no "Estudo para uma bailadora andaluza" (p. 195-201) e também em "Habitar o flamenco" (p. 368-369). Para conhecer o flamenco inteiramente, é necessário aproximar-se em separado a cada uma das partes que constituem a sua origem - a língua, os nativos, o bairro, a moral e o tempo:

\footnotetext{
6 "A Antonio Mairena, Cantador de flamenco" (p. 511-512).

7 “(...) de los hijos de las sombras, los habitantes de las cuevas, de las cárceles, de las minas, de los prostíbulos".
} 
N. T. S. PEdra João Cabral e o flamenco ou a arte de fazer no extremo

\author{
A linguagem: um falar com coisas \\ e jamais do oito mas do oitenta; \\ seus nativos: todo uma gente \\ que existe espigada e morena; \\ seus bairros: todos os sotaques \\ em que divide seus acentos; \\ sua moral: a vida que se abre \\ e se esgota num instante intenso; \\ seu tempo: borracha que estica \\ em segundos de passar lento, \\ lento de sesta, sesta insone \\ em que se está aceso e extremo.
}

Tudo na origem desta arte parece poder resumir-se à precisão e ao extremo já destacados e que, em muito, aproximam-se do exercício de criação cabralino. A substantivação da linguagem, neste falar com coisas, nestes fiapos de língua ("Na cava, em Triana", p. 633-634) nos quais a fala se faz no extremo do oitenta remete-nos à coisificação cabralina, aos versos de palavras medidas e concisas. Também a moral de viver num instante intenso e neste tempo aceso e extremo que consome a vida e o poema. Contudo, nestes versos também há lugar para uma apreensão do perfil desta gente flamenca: de falar simples, espigada e morena, vinda de todos os lugares, que vive intensamente porque não sabe quanto dura o seu tempo.

Originário dessas gentes, o flamenco carece de tradição escrita. O caráter popular imprime-se, então, não apenas no fato de os seus criadores não saberem nem ler nem escrever, mas na consequente retomada da principal característica das composições populares medievais, que tanto chamou a atenção ${ }^{8}$ de João Cabral: os versos nunca estão completamente feitos, mas sempre estão sendo feitos. Observando a relação mantida pelo poeta com a literatura medieval espanhola, verificamos que ela se concretiza muito mais nos limites da forma - na estrutura que imita a prosa, em versos - que do conteúdo. Não será diferente no que concerne aos versos flamencos. A presença pouco significativa da poesia flamenca nos versos cabralinos se dá, ao nosso entender, pela temática nela desenvolvida. Como os primeiros cantares ibéricos, é muitas vezes de um delicado panteísmo, de exaltação de um amor ou de uma pessoa definitivamente ausente, como se verifica nas seguintes coplas (apud FERNÁNDEZ BAÑULS, 2009):

Revista Letras,

8 "Gosto muito do flamenco, mas da literatura primitiva ainda mais" (MELO NETO apud EXTREMERA TAPIA e TRÍAS, 1993, p. 57).
Curitiba, UFPR,

n. 102 , pp. $27-46$,

jul./dez. 2020

ISSN 2236-0999

(versão eletrônica) 
Pa’ qué me dijiste

Que iba' a venir,

Que me he llevado to' la

noche en vela,

Sin poder dormir.
A sándalo y a romero

Huele tu cuerpo;

No he visto en la morería

Jazmín más tierno.
Fui piedra y perdí mi centro

Y me arrojaron al mar,

$\mathrm{Y}$, a fuerza de mucho tiempo,

Mi centro vine a encontrar.

\title{
E lemos nas palavras de Guitiérrez Carbajo:
}

\begin{abstract}
A poesia flamenca canta tudo o que acontece ao ser humano, com suas debilidades, suas carências e suas grandezas, mas em algumas ocasiões mantém um diálogo com outros elementos da natureza, como o vento, a lua, as pedras e os pássaros. A copla flamenca em várias ocasiões se manifesta como a expressão individual de uma dor e, em outros casos, se faz solidária do sentimento dos demais (GUITIÉRREZ CARBAJO, 2007, p. 86) ${ }^{9}$.
\end{abstract}

Em apenas dois poemas João Cabral referencia o amor das coplas flamencas. Na voz de "Manolo Caracol" (p. 639-640) e de "Niña de los peines" (p. 643):

\section{(...) \\ Canta a partir da íntima fenda \\ E sempre pensa que uma fêmea}

\author{
que com a navalha dos olhos \\ abriu-lhe fundo com seu ódio \\ ferida que de dia esconde \\ para que de noite ele sonde \\ onde é que se localiza \\ (mas não quer curá-la, é seu guia) \\ (...) \\ Mas no flamenco o amor aponta \\ como punhal entre margaridas. \\ O flamenco fala do amor \\ como ele, também floralmente,
}

9 La poesía flamenca canta todo lo que le sucede al ser humano, con sus debilidades, sus carencias y sus grandezas, pero en ocasiones entabla una conversación con otros elementos de la naturaleza, como el viento, la luna, las piedras y los pájaros. La copla flamenca que en múltiples ocasiones se manifiesta en una expresión individual de la pena o de la queja, en otros casos se hace solidaria del sentir de los demás. 
N. T. S. PEDRA João Cabral e o flamenco ou a arte de fazer no extremo mas no flamenco um punhal oculto

nesse canteiro cresce sempre.

O romantismo das primeiras coplas cede lugar a um sentimento mais passional, muito mais extremo, no flamenco-cabralino. Amor e ódio são colocados lado a lado, como a mão e o punhal. É a ameaça do corte, ou a própria ferida, que nutre o cante e a poesia.

O distanciamento do conteúdo temático, contudo, não diminui a admiração do poeta pelas imagens concretas oriundas destas coplas flamencas ${ }^{10}$ que prezam pela simplicidade, síntese e precisão. A matéria concreta tão estimada por João Cabral é também característica dos versos flamencos nos quais - segundo Federico García Lorca em sua Arquitectura del cante hondo (2000, p. 147) - os objetos assumem uma personalidade aguda e chegam a formar parte ativa na ação lírica.

A objetividade, a síntese e a precisão presentes nas coplas flamencas também são caras ao fazer poético cabralino. Segundo Guitiérrez Carbajo "a copla flamenca tem, entre outras maravilhosas potencialidades, a capacidade de expressar o máximo com o mínimo"11 (GUITIÉRREZ CARBAJO, 2007, p. 44). A expressão do máximo no mínimo se faz presente nos versos de João Cabral, não só pelo uso de imagens concretas, da coisa que diz muito por si só, mas também pelo emprego de uma forma contida, de versos enxutos, que possibilitam a visualização desta condensação. Assim, se as coplas se organizam geralmente em uma estrofe de quatro versos, nos quais são apresentados os temas anteriormente expostos, a recorrência do número quatro também é grande na organização estrófica dos versos de João Cabral.

Se o poeta se distancia do motivo flamenco caracterizado não apenas pelo panteísmo, mas também pela representação artística da tragédia humana, da paixão e da catarse, parece paradoxal a sua atenção ao cante e baile, entendidos como a parte de um todo denominado flamenco. No entanto, os dois poemas mais analisados pela crítica sobre o universo flamenco presente na poética cabralina - "Estudos para uma bailadora andaluza" (p. 195-201) e "A palo seco" (p. 223-227) - respondem à questão. Cante e baile não se tornam motivos poéticos pela inspiração, mas são trabalhados por João Cabral, que encontra nos adjetivos empregados ao flamenco que se oporiam a seu fazer poético - passional, doloroso, trágico - o mesmo elo encontrado na relação com o mundo taurino: viver/escrever no extremo, no limite. Deste modo, nos dois poemas anteriormente citados e, vale lembrar, os mais extensos de

10 "[o flamenco] é um gênero muito especial. Tem a letra, tem essa concretude da poesia primitiva espanhola de Góngora, e até inclusive de Lorca. 'Los ojitos de tu cara tienen los cristales muertos 'é uma mineralização duma coisa animal: los ojos. Depois volta a animalizar uma coisa que não morre, como os cristais. Isso é o que eu chamo de objetividade: a concretude do flamenco" (MELO NETO apud EXTREMERA TAPIA e TRÍAS, 1993, p. 56). 11 "(...) la copla flamenca encierra, entre otras maravillosas potencialidades, la capacidad de expresar lo máximo con lo mínimo”.
Revista Letras,

Curitiba, UFPR,

n. 102 , pp. $27-46$,

jul./dez. 2020

ISSN 2236-0999

(versão eletrônica) 
João Cabral sobre o universo espanhol, o poeta procura encontrar bailaora e cante na sua forma mais essencial, no limite da sua existência, despindo-os de qualificativos e apresentando-os em sua forma mais original.

Em carta datada em 21 de janeiro de 1957, João Cabral escreve ao amigo Antônio Houaiss: "Como em matéria de tauromaquia pouco me resta que aprender (desculpe a imodéstia), estou aproveitando esta estada na Espanha para me embrenhar um pouco no cante e no baile andaluz (com o enorme handicap de minha inaptidão musical)" (MELO NETO apud HOUAISS, 2007). Desde a relação do poeta com a tauromaquia, o verbo "embrenhar-se" aplica-se com duplo significado: o da vivência e o do estudo. Não apenas as visitas às cuevas flamencas lhe proporcionam a assimilação do cante e do baile. O grande domínio que o faz ser capaz de marcar as diferenças entre os cantes e os palos, registrado no conhecimento das canções e ritmos utilizados para cada ocasião, também será alcançado pela realização de leituras sistemáticas e da consequente elaboração do visto e estudado em material poético. Exemplo desta elaboração anteriormente citada é o poema "Numa sexta-feira Santa" (p. 566-568).

Empregando mais uma vez o estilo narrativo, a voz poética em terceira pessoa conta a experiência vivida na Semana Santa da cidade de Utrera. Vale lembrar o caráter solene dessas festas no sul da Espanha, da peregrinação dos Cristos pela rua, da legião de confrarias que se organizam em lentas marchas penitentes, da reconstituição da dor dos Cristos crucificados. Acontece que, naquela Semana Santa, a cantaora Pepa, grande por bulerías, iria cantar pela primeira vez as saetas ${ }^{12}$, acompanhando a entrada do Cristo cigano na Igreja Matriz de Utrera. E então o poeta registra os seguintes versos:

\author{
Passa que cantar por saetas \\ cante que aceita a própria Igreja, \\ faz-se com o mesmo compasso \\ das siguiriyas, que os ciganos \\ carregam no pulso e na língua \\ para confusão da polícia.
}

Tanto a saeta quanto a siguiriya ${ }^{13}$ são cantos dramáticos, fortes e sombrios, com um compasso bastante similar. A diferença entre eles é notada

12 Reza ou pregaria que é dirigida diretamente a Deus ou a Virgem Maria. Canto popular estendido por toda a Espanha que tem por objetivo incitar a devoção e a penitência e que se pratica como canto da Paixão de Cristo. (BLAS VEGA, José. Diccionario enciclopédico ilustrado del flamenco. Madrid: Cinterco, 1988).

13 Canto dramático, forte, sombrio e desolador. Considerado um dos mais representativos do flamenco. As letras de suas coplas são tristes, sentimentais e refletem a tragédia humana, seus sofrimentos e dores em relação aos eternos temas do amor, da vida e da morte (BLAS 
N. T. S. PEdRA João Cabral e o flamenco ou a arte de fazer no extremo quase somente no teor das coplas, por isso é surpreendente o conhecimento tão preciso alcançado por João Cabral.

O equívoco de Pepa, sua ida até a delegacia pela sacrílega infração anotada por um guarda-civil competente/ em flamenco e a posterior liberação sem mais incidentes, proporciona a este espectador - que assim mesmo se denomina nos versos: Sendo ele o só espectador - conhecer o verdadeiro flamenco, não o representado nos cafés e cuevas turísticas, mas o tão íntimo, tão extremo, tão doloroso que pode ser comparado ao sentimento vivido na Semana Santa, sem que isto seja uma blasfemia:

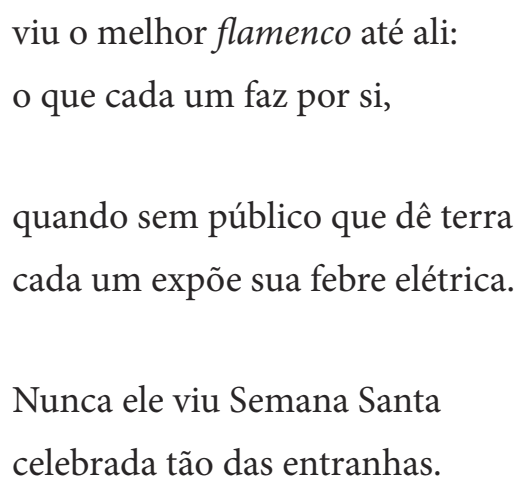

Ainda que mais de uma vez João Cabral afirme a sua inaptidão auditiva e o seu gosto pelo visual 14, "Numa sexta-feira Santa" (p. 566-568) e os demais poemas de motivos flamencos demonstram o contrário. Os poemas dedicados ao cante aparecem em maior número que os dedicados ao baile e se lê neles uma aguda composição e um profundo conhecimento do universo musical do cante flamenco. Entre estes poemas merece atenção a organização da trilogia "A palo seco" (p. 223-227); "El cante hondo" (p. 348) e "Ainda el cante flamenco" (p. 362), que sintetiza não apenas o encontro do poeta com o canto andaluz, mas o conhecimento que desenvolve sobre esta arte. A distinção do ritmo - palo seco -, do cante jondo e do cante flamenco já seria suficiente para demonstrar o domínio teórico alcançado pelo poeta, afinal, embora muitas vezes considerados como um único, cada um dos cantes se organiza em uma estrutura própria. Entretanto, parte do que caracteriza o trabalho de criação de João Cabral é a inversão que realiza dos cantes, isto é, se o cante flamenco é o mais conhecido e genérico, que na sua estrutura alberga o cante jondo, que por sua vez tem entre os seus ritmos o palo seco, o poeta inverte a ordem, trabalha com o mais "primitivo", com o ritmo de origem até alcançar a forma mais conhecida e popular que é o cante flamenco.

Também é relevante observar o didatismo e intelectualismo desta série de poemas. Em cada um deles é possível encontrar a definição do elemento proposto no título obedecendo a um sentido inverso ao da apresentação dos

VEGA, José. Diccionario enciclopédico ilustrado del flamenco. Madrid: Cinterco, 1988). 14 "A música andaluza se associa a movimento de dança, torna-se visual. Aí eu gosto" (MELO NETO apud CARDOSO, 2007, p. 197).
Revista Letras,

Curitiba, UFPR,

n. 102 , pp. $27-46$,

jul./dez. 2020

ISSN 2236-0999

(versão eletrônica) 
versos, ou seja, se João Cabral se volta às origens para depois ampliar o cante, nas definições dadas ao longo dos versos o poeta transpõe os significados originais e os amplia, dando-lhes uma abrangência que supera, muitas vezes, a referencialidade do flamenco. É o que sucede em "A palo seco" (p. 223227), por exemplo. Mais uma vez utilizando a sua série de quatros - quatro fragmentos, divididos em outros quatro fragmentos, compostos por duas estrofes de quatro versos - o poeta define nos primeiros oito versos o sentido literal do termo palo seco:

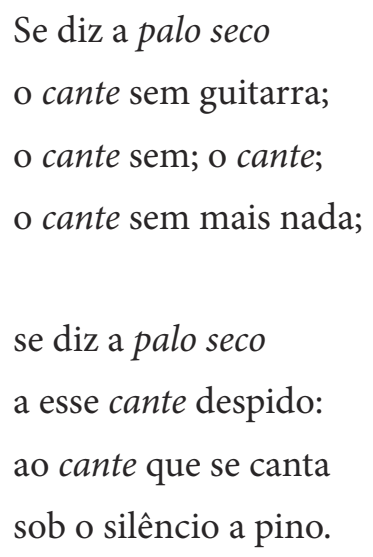

Partindo da definição conhecida pelo senso comum e reforçada pelo uso do "se diz" o poeta inicia uma série de outras definições para designar este cante. E, a partir da terceira estrofe, já não se diz, o cante a palo seco "e’" ou "não é", alguma coisa, coisas estas que compõem o universo cabralino. $\mathrm{E}$ então, existem situações e objetos a palo seco:

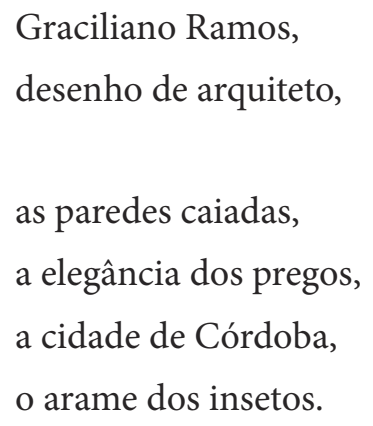

Como também é a palo seco o fazer poético cabralino que pode ser lido em cada uma das comparações realizadas ao longo do poema. Assim, como o cante a palo seco, também seus versos são secos como o deserto, cortantes como lâminas e diamantes, solares como o meio-dia, extremos como o grito e se sintetizam no não se aceitar o seco/por resignadamente,/ mas de empregar o seco/ porque é mais contundente. Nas palavras de Ángel Crespo e Pilar Gómez Bedate: 
N. T. S. PEDRA João Cabral e o flamenco ou a arte de fazer no extremo palo seco, criou, no poema que recebe este título, o cânone da poesia que, para ele, deve ser, como é o cante ao que se refere, difícil pela sua nudez, seca e pura, sem acompanhamento de nenhuma música, unida à ideia construída e dominada pela vontade clarividente do poeta como o cante sem violão é dominado pelo cantaor, cuja voz não se esvanece, mas se eleva segura e firme contrária ao pesado silêncio de onde nasce (CRESPO e GÓMEZ BEDATE, 1964, p. 324) $)^{15}$.

Nas palavras dos críticos espanhóis se evidencia, mais uma vez, o trabalho de construção a que João Cabral submete os seus versos. A imagem do cantaor que, desacompanhado mantém a sua voz segura e firme antes do nascimento do seu cante, apesar do silêncio que o circunda, pode ser perfeitamente transposta ao poeta, que com mão segura e firme, no trabalho solitário de composição, enfrenta o profundo e longo silêncio antes da concretização dos versos.

Seguindo a organização de partida - do mais interno para o mais externo -, o poeta dedica agora duas quadras a "El cante hondo" (p. 348), que contém, entre outros ritmos, o a palo seco. Continua valendo para este poema a regra do intelectualismo observada no poema anterior; desta vez, o poema se constrói a partir da constatação da pouca - ou nenhuma - distinção que se faz entre o cante jondo e o cante flamenco: $O$ cante hondo às mais das vezes/ desconhece esta distinção. Chama a atenção, porém, o gosto de João Cabral pelo cante jondo, este lamento mais gemido que acaba em explosão. Se o cante a palo seco é aproximado ao seco exercício da escrita do poema, parece difícil justificar uma identificação do poeta - e do seu fazer poético - com um cante no qual predominam o instinto criador e a intensidade emotiva, em suma, “'a língua do coração' e isso significa que nesta arte não é o intelecto quem fala, mas a paixão e os sentimentos"16 (MARTÍNEZ HERNÁNDEZ, 2004, p. 35).

Ao nosso ver, dois são os aspectos que justificam o interesse e a aproximação do poeta ao cante jondo, a saber: o seu caráter primitivo - seja na forma de expressão popular ou na organização rítmica - e, mais uma vez, a realização no extremo, no limite entre a voz e o grito.

O caráter popular do flamenco, originado no encontro de várias vozes, faz do cante jondo o instrumento para a perpetuação de uma memória coletiva, atribui-lhe o valor de uma voz que nasce da necessidade expressiva de

15 Es João Cabral un entusiasta y gran conocedor del cante y el baile flamencos, y de una modalidad del cante grande, el cante a palo seco, ha hecho, en el poema así titulado, el canon de la poesía que, para él, debe ser, como lo es el cante a que se refiere, difícil por su desnudez, seca y pura, sin acompañamiento de música alguna, ceñida a la idea estrictamente construida y en todo momento dominada por la voluntad clarividente del poeta como el cante sin guitarra es dominado por el cantaor cuya voz no se desmanda, sino que se eleva segura y firme en contra del pesado silencio en el que nace.

16 “(...) 'la lengua del corazón' y con ello se significa que en ese arte no es el intelecto

Revista Letras, quien habla, sino la pasión y los sentimientos".
Curitiba, UFPR,

n. 102 , pp. 27-46,

jul./dez. 2020

ISSN 2236-0999

(versão eletrônica) 
um povo e que, portanto, deve adaptar-se à sua forma de expressão. Federico García Lorca assim registra os elementos constituintes do cante jondo:

\footnotetext{
(...) os elementos essenciais do cante jondo são: o enermonismo como meio modulante, o uso de um âmbito melódico tão reduzido que quase não ultrapassa os límites de uma sexta e o uso repetido e até mesmo obsessivo de uma mesma nota. (...) Por isto o cante flamenco, e especialmente a seguiriya cigana, nos dá a impressão de uma prosa cantada, destruindo toda a sensação de um ritmo métrico, ainda que os textos de seus poemas sejam tercetos ou quartetos assonantes (GARCÍA LORCA, 2000, p. 125) ${ }^{17}$.
}

Várias aproximações à obra poética cabralina podem ser realizadas a partir da anterior citação de García Lorca. Sob o ponto de vista temático, se no cante jondo há um reduzido e obsessivo conjunto de notas, nos versos de João Cabral há um reduzido e obsessivo universo de palavras. Interessa-nos destacar, no entanto, a impressão de "prosa cantada" que se registra no cante jondo. Nos versos de João Cabral, por trás da aparente prosa há um árduo trabalho com o verso, notado tanto na sua organização métrica, quanto rítmica.

Então, a compreensão da organização rítmica do cante jondo possibilita entender por que a sua musicalidade desperta a atenção de João Cabral. O encontro do poeta com o ritmo flamenco se faz na essencialidade. Tanto o cante jondo quanto o ritmo a palo seco estão organizados em sistemas musicais primitivos que são tão somente um balbucio perfeito, uma ondulação melódica que rompe a prisão sonora do pentagrama da música, ainda segundo Federico García Lorca (GARCÍA LORCA, 2000, p.116). De modo semelhante, estruturando ritmicamente a seus versos, João Cabral retorna às formas originárias, seja contendo os elementos facilitadores - como é a melodia -, seja empregando as formas fixas espanholas mais populares, como a cuaderna vía e a redondilha.

Sobre a questão, valem ainda as palavras de Manuel de Falla, para quem a voz do "cante jondo é uma voz próxima ao canto do pássaro, ao grito do animal, aos sons da natureza"18 (FALLA apud MARTÍNEZ HERNÁNDEZ, 2004, p. 50). É essa voz-limite que também pode ser lida nos versos do poema:

17 (...) los elementos esenciales del cante jondo son: el enarmonismo como medio modulante, el empleo de un ámbito melódico tan reducido que rara vez traspasa los límites de una sexta, y el uso reiterado y hasta obsesionante de una misma nota. (...) Por este modo llega el cante jondo y especialmente la siguiriya gitana a producirnos la impresión de una prosa cantada, destruyendo toda sensación de ritmo métrico, aunque en realidad son tercetos o cuartetos asonantados los textos de sus poemas.

18 “(...) cante jondo es una voz cercana al canto del pájaro, al grito animal, al sonido de los elementos de la naturaleza”. 
João Cabral e o

flamenco ou a

arte de fazer no

extremo
N. T. S. PEDRA

(...)

o seu lamento mais gemido

acaba em explosão.

Tão retesada é a sua tensão,

tão carne viva seu estoque,

que com desembainhar-se em canto

rompe a bainha e explode.

No último poema da trilogia sobre o cante em versos cabralinos, "Ainda el cante flamenco" (p. 362), encontramos, como já havíamos anunciado, o seu registro mais coloquial. Destaca-se, entretanto, o aparecimento do advérbio ainda. Ainda há coisas a se dizer sobre o cante. Contudo, as coisas ditas no poema não são inéditas, reafirmam a escolha musical feita por João Cabral para os seus versos, já registrada nos dois poemas anteriores:

\author{
É a música desejada \\ como o que não adormece: \\ o mais contrário do embalo \\ e do canto emoliente. \\ $\mathrm{Na}$ Andaluzia esse canto \\ insonífero se atende: \\ a contrapelo, esfolado, \\ arrepiando a alma e o dente.
}

Ao cantar jondo e ao palo seco, extremo e solitário o poeta une o cante flamenco de expressividade emocional sublimada e contida. Encontra, na conjunção de todos eles, a música desejada, a música que consegue sintetizar os poemas contrários ao embalo e ao emoliante. O ritmo que sustenta os versos é então o a contrapelo, esfolado, ritmo que arrepia a alma e o dente não pela emoção que causa, mas pelo timbre cortante - de faca e de pedra - que representa.

Os poemas dedicados ao cante também nos possibilitam estabelecer uma aproximação entre a figura do poeta e a do cantaor. Diz-se que o intérprete do cante jondo se situa na fronteira entre o grito e a linguagem articulada, a natureza e a cultura, a paixão e a razão e que desta condição fronteiriça, limítrofe, sentida com tensão, obtém toda força e originalidade para a execução do seu cante. Essas palavras ecoam no já citado poema cabralino "A Antonio Mairena, Cantador de flamenco" (p. 511-512):

Existir como quem se arrisca

como nesse cante em que se atira:

Revista Letras,

Curitiba, UFPR,

n. 102 , pp. $27-46$,

jul./dez. 2020

ISSN 2236-0999

(versão eletrônica) 


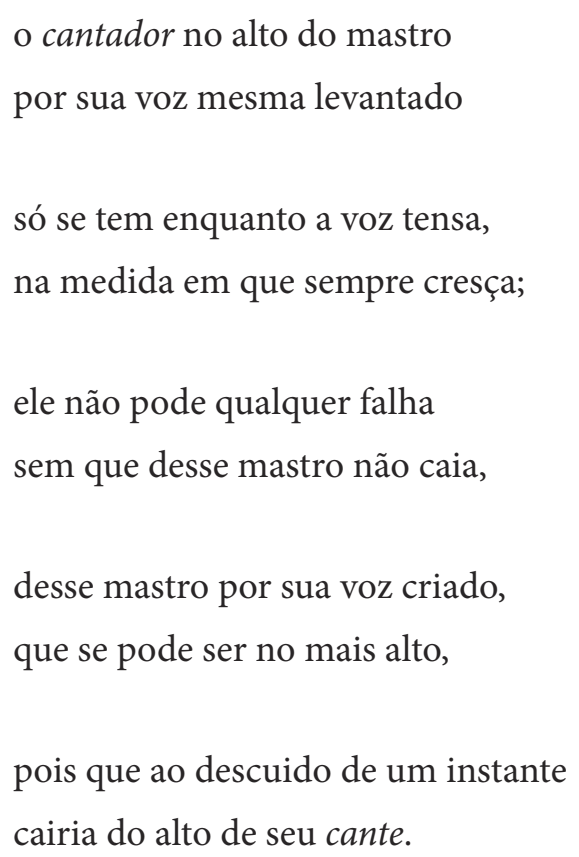

O risco do cante assemelha-se ao do escrever versos nesta aguda linha que separa a inspiração da construção, no controle a que se impõe o poeta para encontrar a precisão. As palavras utilizadas por Edgar Neville para caracterizar o cantaor ampliam a discussão: "Para mim, o melhor cantaor é o que se queima no transe supremo do seu cante, e rompe suas artérias procurando a voz que expresse exatamente a pena da sua alma, e ao terminar a copla caia morto no chão, enquanto o cante continua vibrando no ar"19 (NEVILLE, 2006, p. 34). E completamos com a confissão de João Cabral: "Saio do poema suando, com picareta. Minha obra é motivo de angústia. O sujeito tem de viver no extremo de si mesmo" (MELO NETO apud JABOR, 2005). No paralelo estabelecido entre o cantaor que termina o seu cante "morto" e do poeta que sai "suando" predomina, como também na arte taurina, o fazer no extremo, só que como a morte na arenal é real, cante da alma extrema, escreve o poeta em "Na cava, em Triana" (p. 633-634). Deste modo, toureiro, cantaor e poeta são feitos símiles na arte da criação e, entre eles, João Cabral escolhe os que, como ele, são, mais que nada, técnica, ofício e sabedoria e que dominam com as mãos ou com a voz a emoção e o arrebatamento.

A aproximação ao baile, a parte mais visual do flamenco, igualmente se constrói no paralelismo entre a figura da bailaora, do toureiro, do poeta, bem como na do pintor/escultor. São apenas dois os poemas dedicados exclusivamente ao baile flamenco - "Estudos para uma bailadora andaluza" (p. 195-201) e "Carmen Amaya, de Triana" (p. 641-642) -, no entanto ambos

19 “(...) Para mí el mejor cantaor es el que se quema en ese trance supremo de su cante, y se rompe las arterias buscando el vozarrón que diga exactamente la pena de su alma, y al terminar la copla caiga en el suelo muerto, mientras que el cante quede vibrando en el aire ingrávido". 
N. T. S. PEdRA João Cabral e o flamenco ou a arte de fazer no extremo corroboram a premissa cabralina de que a arte deve ser construída e despida de todos os artefatos.

Nos cento e noventa e dois versos divididos em seis grupos de oito estrofes, arranjadas em quatro versos de redondilha maior de "Estudos para uma bailadora andaluza" João Cabral retorna ao terreno visual realizando um estudo plástico da dança e da bailaora. Contudo, na figura estudada por todos os ângulos, cuja dança sempre acaba/ igual que como começa, é possível encontrar mais uma lição de estética.

A dança executada pela bailaora de João Cabral é a seguiriya, que, como o cante, caracteriza-se pela sua intensidade e dramaticidade. É, segundo Eulalia Pablo e José Navarro, "uma dança austera, sóbria, vigorosa, cerimonial, na qual não são admitidos adornos fáceis e não cabem concessões gratuitas para o espetáculo. Interpreta-se com um compasso lento e pausado"20 (PABLO e NAVARRO, 2007, p. 24). Não é apenas na austeridade que o baile se aproxima à pintura, ao toreo e à escrita, mas também em outra série de elementos que, além de colocá-lo como parte integrante, reafirma a inter-relação existente entre o fazer cabralino e as artes espanholas. Assim, como nas demais relações estabelecidas pelo poeta, o baile é igualmente um exercício solitário, realizado no limite. A bailaora compartilha com os demais artistas o mesmo gosto dos extremos // (...) // no gosto de chegar ao fim/ do que dele se aproxima.

Já na execução do seu baile, não é o público que interessa, é um baile introvertido, de movimentos fechados, sem grandes deslocamentos nem saltos. Realiza uma dança recolhida sobre si mesma, com isolamento e precisão, como quem olha para dentro, como se registra nos versos de "Intimidade do flamenco" (p. 645-646): aquele fazer de mais dentro,// centrarse, viver seu caroço/ e a partir dele dar-se todo.

Característica fundamental para valorar a estética de um baile é a forma com que são realizados os seus passos e movimentos. Quando bem executados, estes devem ser limpos e bem definidos. É uma dança objetiva, "dança dançada e nunca dança sentida" como afirma Luiz Costa Lima (COSTA LIMA, 1995, p. 302). O controle da inspiração faz-se na bailaora como no touro de lidia, que na entrada do tablao-ruedo procura, altiva, alguma presença que a modele:

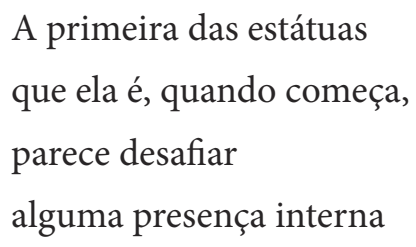

20 "(...) un baile austero, sobrio, recio, ceremonial, en el que no se admite adornos fáciles y donde no caben concesiones gratuitas a la espectacularidad. Se interpreta con un compás lento y pausado".
Revista Letras,

Curitiba, UFPR, n. 102 , pp. $27-46$, jul./dez. 2020 ISSN 2236-0999 (versão eletrônica) 
que no fundo dela própria,

fluindo, informe e sem regra,

por sua vez a desafia

a ver quem a modela.

Ao contrário do embate da corrida, é ela mesma quem se modela, na capacidade de incendiar-se sozinha. Esta capacidade é desenvolvida pelo vínculo estreito que mantém com a terra, com a realidade que tal contato lhe proporciona. No telegráfico contato que estabelece com as suas raízes - seja do tablado ou de sua vida - reafirma a concisão e a secura do seu baile - linear, numa só corda/ em ponto e traço concisa.

No processo de desenvolvimento da sua dança se assiste, finalmente, o despir-se dos artefatos para o encontro da essencialidade. No último grupo de versos, o poeta desfolha a bailaora das suas roupas e gestos:

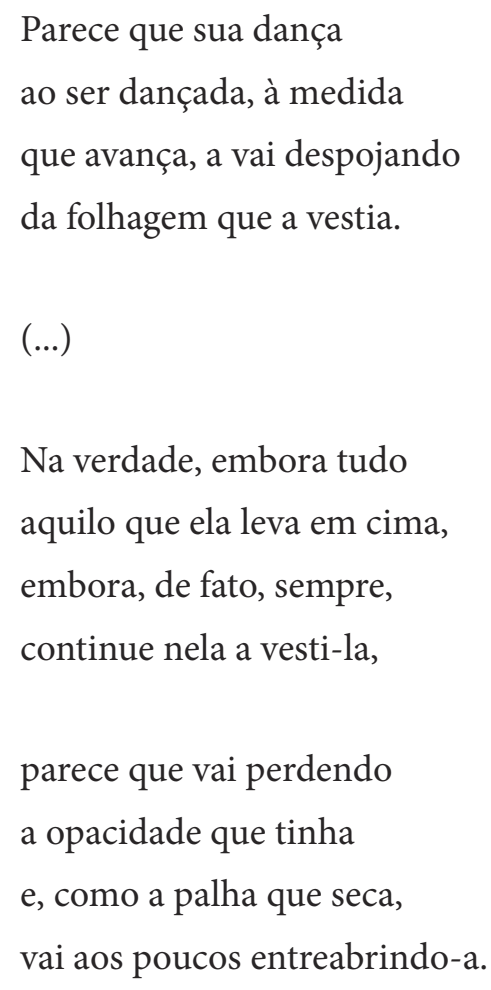

O poeta encontra, nesta espiga, o centro do baile flamenco, despido de qualquer artifício, de qualquer excesso. Conservará em sua vista a essência rítmica e agônica do flamenco, a relação íntima que este mantém com o material, com o concreto, com a forma, com a construção, despindo-o, ao "desvestir" a bailaora, do rótulo venal de artigo de exploração folclórica.

Depois de observar por vários ângulos a bailaora e chegar ao centro do seu baile o que era um estudo genérico se personifica na figura de "Carmen Amaya, de Triana” (p. 641-642). Da organização formal do poema, destaca-se a sua estrutura narrativa. Todo ele está construído, nas palavras da bailaora, no relato da sua opção pelo flamenco e, especialmente, na procura de ser reconhecida pela exclusividade do seu baile: 
N. T. S. PEDRA João Cabral e o flamenco ou a arte de fazer no extremo

\author{
Tinha então de ganhar a vida, \\ e como eu, mais de mil havia. \\ Onde ir buscar esse sotaque \\ que entre as dez mil me destacasse \\ e fizesse dizer: - Eis a Amaya, \\ eis seu bailado, vivo e em chaga.
}

Vale destacar ainda entre as considerações de aspecto formal a ampliação do dicionário espanhol do poeta. Com não menos rigor que o empregado para as terminologias do cante, transita entre as distintas modalidades de baile - as sevilhanas e o flamenco e, no flamenco, as seguiriyas - com a segurança do bom conhecedor.

No entanto, é a escolha do motivo que proporciona uma nova aproximação ao diálogo estabelecido entre as artes. Se em "Estudos para uma bailadora andaluza" a bailaora é uma estátua como que talhada em pedra, Carmen Amaya assume o lugar do escultor, é ela que cria o seu baile, em versos que nos remetem indiscutivelmente ao estudo do poeta sobre Joan Miró. Do mesmo modo que para Carmen Amaya "Dançar não é coisa aprendida,/ mas o aprender-se cada dia.// Assim é que entendo a lição;/ sabê-la, mas segui-la, não.// Fugir do que ela faz de gesso/ dançá-la, mas sempre do avesso, para João Cabral o bom pintor/escultor é aquele que limpa o olho do visto e a mão do automático para colocar-se numa situação de pureza e liberdade diante do hábito e da habilidade (MELO NETO, 2008, p.691). Não se desconsidera a lição, mas sobre ela prevalece a constante, e renovada, criação.

Neste exercício de criação sob a técnica dominada evidencia-se novamente o fazer no extremo, no risco. O sotaque mais forte é encontrado pela bailaora na arte do toreo, na luta com a morte que faz mais denso - e tenso - o gesto:

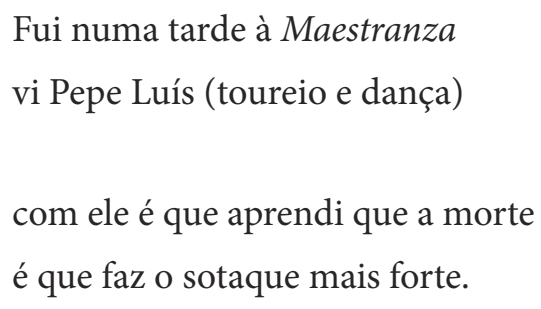

Não é o medo da morte, que só virá em meu dia certo, que acentua os seus movimentos e os do toureiro, tampouco a voz do cantaor e do poeta. A morte é o desafio do fazer a contrapelo, no avesso, como no limite do fogo, deste gosto compartilhado por todos eles de chegar ao $\mathrm{fm} /$ do que dele se
Revista Letras,

Curitiba, UFPR,

n. 102 , pp. $27-46$,

jul./dez. 2020

ISSN 2236-0999

(versão eletrônica) 
aproxima, / gosto de chegar ao fim, de atingir a própria cinza. Gosto de chegar ao fim da criação, depois de tê-la vivido no extremo, de ter-se arriscado, com a segurança da lição aprendida, no movimento novo, seja na dança, no ruedo, na tela ou no papel.

Dentre as relações estabelecidas por João Cabral com a arte do flamenco, além do relevante diálogo entre os dois tipos de criação, parecenos, finalmente, importante acentuar a espacialidade e a visualidade que o poeta atribui a esta arte. Como vimos no poema "Habitar o flamenco" (p. 368-369), cante e baile se materializam e podem ser habitados como se habita uma cidade, conhecendo-se a sua linguagem, os seus nativos, os seus bairros, os seus costumes, a sua ideologia e o seu tempo.

Deste modo, a aproximação do poeta às artes espanholas, o rigor do seu estudo e a precisão dos versos desenvolvidos sobre esta temática preparam o encontro de João Cabral com aquela que, como Recife, conseguiu (des)ferilo até a poesia: Sevilha. 
N. T. S. PEDRA João Cabral e o flamenco ou a arte de fazer no extremo

\section{Referências}

BLAS VEGA, José. Diccionario enciclopédico ilustrado del flamenco. Madrid: Cinterco, 1988.

CADALSO, José. Cartas marruecas. Disponível em: http://www. cervantesvirtual.com/servlet/SirveObras/01471731988025951976602/index. htm. Acesso em: 10 dez. 2009.

CARDOSO, Helânia Cunha de Sousa. A poesia de João Cabral de Melo Neto $e$ as artes espanholas. Tese (Doutorado) - Universidade Federal de Minas Gerais, Belo Horizonte, 2007.

COBALEDA, Mariate. El simbolismo del toro. La lidia como cultura y espejo de la humanidad. Madrid: Biblioteca Nueva, 2002.

COSTA LIMA, Luiz. Lira \& Antilira. Rio de Janeiro: Topbooks, 1995.

CRESPO, Ángel; GÓMEZ BEDATE, Pilar. Poemas sobre España de João Cabral de Melo. Cuadernos Hispanoamericanos. Madrid: Instituto de Cultura Hispánica. n. 177, 1964, p. 320-351.

DAVILLIER, Charles de; DORÉ, Gustavo. Viaje por España. Madrid: Castilla, 1957.

EXTREMERA TAPIA, Nicolás; TRIAS, Luisa. Conversa em casa do poeta João Cabral de Melo Neto, a praia do Flamengo, em 14 de julho de 1993. Maresia. Revista de la Asociación de los lusitanistas del estado español, n. 1, p. 54-59, 2006.

FERNÁNDEZ BAÑULS, Juan Alberto. Copla flamenca y copla tradicional. Disponível em: http://www.lyraminima.culturaspopulares.org/actas/ sevilla/43-fernandez.pdf. Acesso em: 23 ago. 2009.

GARCÍA LORCA, Federico. Arquitectura del cante hondo. Granada: Comares, 2000.

GUTIÉRREZ CARBAJO, Francisco. La poesía del flamenco. Madrid: Almuzara, 2007.

HOUAISS, Antônio.Memorial Antônio Houaiss. Correspondências. Disponível em: http://www.cebela.org.br/MemorialHouaiss/MHcorrespondenciasDet. asp. Acesso em: 4 jun. 2007.
Revista Letras,

Curitiba, UFPR,

n. 102 , pp. 27-46,

jul./dez. 2020

ISSN 2236-0999

(versão eletrônica) 
JABOR, Arnaldo. João Cabral mostrou o que a poesia poderia ser. Diário do Nordeste, Fortaleza, 19 de out. 1999. Disponível em http://www.secrel.com. br/jpoesia/arnald02.html. Acesso em: 15 maio 2005.

MARTÍNEZ HERNÁNDEZ, José. Poética de Cante jondo (una reflexión estética sobre el flamenco). Murcia: Nausicaa, 2004.

MELO NETO, João Cabral de. Obras completas. Org. Antônio Carlos Secchin. Rio de Janeiro: Nova Aguilar, 2003.

NEVILLE, Edgar. Flamenco y el cante jondo. Madrid: Rey Lear, 2006.

PABLO, Eulalia; NAVARRO, José Luis. Figuras, pasos y mudanzas. Claves para conocer el baile flamenco. Madrid: Almuzara, 2007.

Submetido em: 13/07/2020

Aceito em: 6/11/2020 